Int. J. Electrochem. Sci., 13 (2018) $2745-2757$

International Journal of

ELECTROCHEMICAL

SCIENCE

WWW.electrochemsci.org

\title{
Degradation of Passive Film on Low-Nickel Stainless Steel in Groundwater with Different Concentration of Chloride Ions
}

\author{
Xingguo Feng ${ }^{1,2,3}$, Ruilong Shi ${ }^{1}$, Leyuan Zhang ${ }^{1}$, Yiwen $\mathrm{Xu}^{1}$, Xiangying Zhang ${ }^{1}$, Jing Zhang ${ }^{1}$, \\ Yunan Ding ${ }^{l}$, Da Chen ${ }^{1}$, Nengpan $\mathrm{Ju}^{2, *}$, Xibing Zhang ${ }^{4}$ \\ ${ }^{1}$ Jiangsu Key Laboratory of Coast Ocean Resources Development and Environment Security, College \\ of Harbour, Coastal and Offshore Engineering, Hohai University, Nanjing 210098, Jiangsu, China \\ ${ }^{2}$ State Key Laboratory of Geohazard Prevention and Geoenvironment Protection, Chengdu University \\ of Technology, Chengdu 610059, Sichuan, China \\ ${ }^{3}$ Shangdong Provincial Key Lab of Ocean Engineering, Ocean University of China, Qingdao 266100, \\ China. \\ ${ }^{4}$ Changjiang River Scientific Research Institute, Wuhan 400010, Hubei, China \\ *E-mail: jnp@cdut.edu.cn
}

doi: $10.20964 / 2018.03 .41$

Received: 16 October 2017 / Accepted: 3 January 2018 / Published: 5 February 2018

\begin{abstract}
The effect of chlorides on the degradation of passivation on a low-nickel stainless steel was investigated via electrochemical testing in a simulated groundwater solution. The results revealed that, with increasing chloride concentration of the groundwater, the corrosion potential, adsorption layer resistance, and the polarization resistance of the steel decreased significantly, donor density increased, whereas the thickness of the space charge layer decreased, and pitting potential decreased significantly (as determined via potential dynamic polarization measurements). The results suggest that degradation of the passive film on the low-nickel stainless steel was considerably exacerbated by increasing chloride concentration of the groundwater.
\end{abstract}

Keywords: Low-nickel stainless steel; Groundwater; Mott-Schottky; Passive film; EIS.

\section{$\underline{\text { FULL TEXT }}$}

(C) 2018 The Authors. Published by ESG (www.electrochemsci.org). This article is an open access article distributed under the terms and conditions of the Creative Commons Attribution license (http://creativecommons.org/licenses/by/4.0/). 